\title{
FGFR3 Protein Variant
}

National Cancer Institute

\section{Source}

National Cancer Institute. FGFR3 Protein Variant. NCI Thesaurus. Code C128903.

A variation in the amino acid sequence for the fibroblast growth factor receptor 3

protein. 